\title{
CHARACTERIZATION OF SHARP POINTS
}

AND EDGES BY ELECTRICAL

BREAKDOWN

Julius Cohen

Product Engineering Division

Center for Consumer Product Technology

Institute for Applied Technology

August 1975

Final

Prepared for

Center for Consumer Product Technology

Institute for Applied Technology

National Bureau of Standards

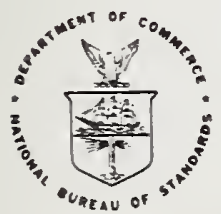

U.S. DEPARTMENT OF COMMERCE, Rogers C.B. Morton, Secretary James A. Baker, III, Under Secretary

Dr. Betsy Ancker-Johnson, Assistant Secretary for Science and Technology

NATIONAL BUREAU OF STANDARDS, Emest Ambler, Acting Director 


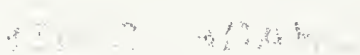

$$
\begin{aligned}
& \text { s: }
\end{aligned}
$$


INTRODUCTION. . . . . . . . . . . . . . . . . . . . 1

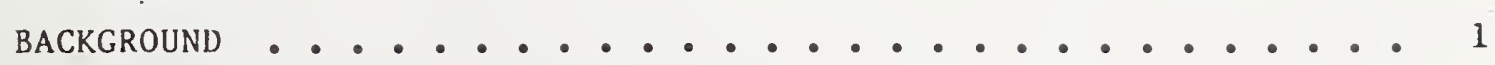

EXPERIMENTAL APPARATUS AND PROCEDURE . . . . . . . . . . . . 2

EXPERIMENTAL RESULTS . . . . . . . . . . . . . . . . 3

1. Negative polarity on specimen .............. . 3

2. Positive polarity on specimen ............. . 4

DISCUSSION . . . . . . . . . . . . . . . . 4

CONCLUSIONS • . . . . . . . . . . . . . . . . . 6

RECOMMENDATIONS • • • . . . . . . . . . . . . . 6

Appendix: Calculation of electric field at the tip of a

hyperboloidal point-to-plane gap.......... 7

Acknowledgment . . . . . . . . . . . . . . . 8

Bibliography .. . . . . . . . . . . . . . . 9 
Some consumer products, especially those of sheet metal, have hazardous sharp edges or points. It is particularly serious if toys are so deficlent, as they are handled by incautious children.

An Instrument has been developed at NBS for characterizing sharp edges by mechanical means with use of a synthetic material as a cut indicator. Evaluation of results requires operator judgement; the device is not applicable to points also, and operation could be tedious if examining long edges.

An electrical breakdown method, if workable, would appear to be advantageous: (1) results might be more accurate and precise; (2) 1t may be applicable to both edges and points; (3) application would be rapid. It was considered worthwhile, therefore, to do a limited pllot study aimed at determining feasibility of using the phenomenon of electrical breakdown of gases to characterize sharp edges and points. This work is described below.

\section{BACKGROUND}

Electrical breakdown in gases is used extensively by industry for many important applications, among these dust removal by electrical precipitation, high-speed printing, electrochemical processes, radiation detection (Geiger counter), ore preparation, de-emulsification of crude o1l-brine mixtures, and discharge of static electricity from surfaces of wool and paper. It may be possible to use the phenomenon also to characterize edges on consumer products as safe or hazardous with regard to potential for causing punctures, cuts, or lacerations.

Electrical breakdown of air or other gases will occur if a sufficiently high voltage is applied through an external circult to two physically separated conductors. If one of the conductors is a sharp point or edge and the other a plane at a suitable distance, the electric field will be very large at the former and small at the latter, and breakdown will be associated with the highly electrically-stressed point.

The discharge may or may not be visible, audible, or olfactible. It may be manifest as a burst, a streamer, or a sustalned glow. In any event the mechanlsms of breakdown are exceedingly complicated and arise when the electric fleld-1nitlated gas plasma reaches a critical state. The plasma, generally containing electrons and lons of both polarities, may be affected by photon emission as well as the electric fleld, and it varies spatially as well as temporally.

In general, breakdown at threshold w111 depend on gas composition (e.g., molsture content in air), point or edge radius and shape, applied potent1al, and gap. Water vapor facilltates breakdown, as do dust specks. 
Figure 1 illustrates the dependence of field at the tip of a point on its sharpness (details of the calculation are given in the Appendix). The radius at the tip is related to focal length, plotted as abscissa; the larger the focal length, the larger the radius and the less sharp the point. The field is seen to be large for very sharp points, or small focal lengths, and to depend sensitively on sharpness over only a very narrow range of focal lengths; for the relatively less sharp points, field is fairly insensitive to degree of sharpness. This suggests that small voltages and small gaps can be used when working with very sharp points, but that use of large voltages and large gaps would be advantageous when trying to characterize points which are not extremely sharp.

Figures 2 and 3 are experimental curves, replotted from the data of other investigators, for the discharge threshold potential of point-toplane gaps vs. radii, with gap lengths as indicated; the former is for positive spherical points, and the latter is for conical points of negative polarity. The qualitative features of the curves shown in both figures are similar: The dependence of threshold potential on radius is greatest for small radil and large gaps, in agreement with the inferences drawn from figure 1 and discussed previously.

Most gas breakdown studies have been made with a positively charged point rather than one charged negatively, as the latter has been found to introduce additional complications: (1) the breakdown being a cathodecontrolled phenomenon is extremely sensitive to the surface properties of the point such as condition, kind of metal, and surrounding gas; (2) threshold potentials are difficult to determine accurately and precisely-the initial currents normally will be very low and falsified thresholds will result from statistical lags; on the other hand, if thermal or photoelectric means is used to emit electrons from the point, too many electrons can mask the threshold.

EXPERIMENTAL APPARATUS AND PROCEDURE

A circuit diagram of the high-voltage breakdown tester is shown in figure 4. A fixed voltage of $2500 \mathrm{~V}$ is applied across a specimen point or edge and parallel plane--initially the gap length is sufficiently large so that breakdown does not occur. By means of the reversing switch, a positive or negative polarity can be imposed on the specimen as desired.

Initially the specimen is made to have positive polarity and the gap length gradually decreased until incipient breakdown is detected by observing the current meter; currents the order of nanoamperes are detectable. Also a neon bulb glows when breakdown occurs. The threshold gap length is then measured by means of a micrometer arrangement. The voltage is then removed, the gap length increased, and the procedure is repeated, but with opposite polarity on the specimen.

In ordinary circuits without voltage regulation, when breakdown occurs the current rises and forces the voltage across the gap to drop. This 
makes determination of the threshold gap length difficult and adversely affects the precision of the measurement. In the present circuit, a diode has been Incorporated, to maintain constant voltage across the gap (prior to breakdown and) during the breakdown process significantly above the threshold of breakdown. This seems to improve the precision of the threshold gap length measurement.

A wide variety of samples were investigated: common household items such as razor blades (dull and sharp), needles, nalls and knives; sheared edges of different metals; and special ground conical points and ground rounded edges of known tip radii and included angles.

\section{EXPERIMENTAL RESULTS}

1. Negative polarity on specimen

Figure 5, a bar graph, shows the threshold gap length required to obtain incipient breakdown when -2500 volts are applied between various objects (including commerclal items) and the plane, known intultively or from experience to be either safe or hazardous. The larger the gap length, the smaller the applied macroscopic fleld, and the more ready the breakdown; sharper objects are assumed to break down easler-1.e. at larger gap lengths-than duller objects. A needle point, the sharpest object tested, is seen to break down at the largest gap length, as expected, and the next sharpest object, a scalpel tip, breaks down at the next largest gap length. On the other hand, dull and smooth edges, incapable of cutting, break down at the smallest gap lengths. Note that the measurements are sensitive enough to distinguish new from used razor blades, new from used saw blades, and rough from smooth edges on sheared metal strips. The kind of metal used for sheared samples, however, had little influence on the results.

A vertical line on the graph arbitrarily drawn at a gap length of 0.52 mm divides the safe from the hazardous objects: If the threshold gap length of an object is $<0.52 \mathrm{~mm}$, the object is found to be safe, if $>0.52$ $\mathrm{mm}$, hazardous.

Figure 6 shows curves of the threshold gap length for special rounded edges of known included angles and edge radii, as indicated. Each solid curve is for a set of edges having equal angles, but different radil; the dashed curve is for edges fabricated as sharp as practicable, and denoted by (zero) 0 radius.

In general, the smaller the included angle and the smaller the radius, the sharper the edge. Note from the solid curves that for included angles $15^{\circ}, 30^{\circ}$ and $60^{\circ}$, the threshold gap length decreases as the edge radius increases (edges become less sharp), as expected; for the $90^{\circ}$ included angle, however, the threshold gap length decreases as the edge radius increases, then becomes essentially constant with increasing radius $c_{f}$ figures 2 and 3 . 
The dashed curve shows that threshold gap length decreases as included angle increases (edges become less sharp), for samples with edges of zero radius. The breakdown of samples with larger radi1 is not well behaved, probably due in part to imprecision in measurement.

Figure 7 shows threshold gap length for special conical points of known Included angles and point radi1, as indicated. Note that as a group the sharpest points (i.e., those with small included angle and tip radius) break down at the largest gap lengths $(>0.5 \mathrm{~mm})$ and the dullest points break down at the smallest gap lengths $(<0.3 \mathrm{~mm})$, which is the desired behavior, but that the individual data points within the group of sharp or dull points do not appear well behaved. The threshold gap lengths of the intermediate points ( $\leq 0.5 \mathrm{~mm}$ and $>0.3 \mathrm{~mm})$ show little dependence on sharpness, or anamolous behavior ( $60^{\circ}$ and $75^{\circ}$ included angle).

\section{Positive polarity on specimen}

Tests made with positive polarity on the specimen generally showed the threshold gap length to be virtually independent of sharpness; the threshold gap length was $\sim 0.5 \mathrm{~mm}$, corresponding to a macroscopic breakdown field of $-50 \mathrm{kV} / \mathrm{cm}$. Exceptions were the sharpest objects such as the needle point, scalpel tip, and the sharpest conical points.

\section{DISCUSSION}

The relative sharpness and hazard potential of some of the special rounded edges had been evaluated prevlously by applying a known force between the test edge and human skin, in vitro, and observing the percent depth of cut, if any. If there were no cut, but only a groove made in the epidermis, we assume here that the test edge is safe. That data shows considerable scatter due to the effect of varlous skin samples (texture, condition, age, etc.) and to imprecision in the test method; nevertheless our appraisal of the data enables a qualitative evaluation of sharpness and hazard potential to be made.

The results of the present work on rounded edges were compared to the skin cut data for test edges restricted to 17.8 newtons (N) (4 poundsforce) and 35.6 newtons ( 8 pounds force). At higher forces, many rounded test edges, safe under normal conditions may cut. The test edges used for human skin cut data are tabulated below according to designation, included angle, and radius.

1

J. R. Sorrells and R. E. Berger, "Some Cutting Experiments on Human Skin and Synthetic Materials", NBS Report NBSIR 73-262 (Oct. 1973). 
Table 1. Test edges used for human skin cut datal

$\begin{array}{ccc}\text { Designation } & \begin{array}{c}\text { Included angle } \\ (0)\end{array} & \begin{array}{c}\text { Radius } \\ (\mathrm{mil})\end{array} \\ \text { A } & 60 & 0 \\ \text { B } & 90 & 0 \\ \text { E } & 105 & 0 \\ \text { F } & 90 & 0 \\ \text { G } & 15 & 2 \\ \text { H } & 30 & 2 \\ \text { I } & 60 & 2 \\ \text { J } & 15 & 4 \\ \text { K } & 90 & 2\end{array}$

Table 2, below, compares the ranking of sharpness obtained from human skin cut data and breakdown data. The comparison is considerd fair, particularly for the shapest specimens; however, as precision of the breakdown data has not been determined, the ranking should be considered approximate and tentative.

Table 2. Comparison of human skin cut data and breakdown data

Human skin cut data

$17.8 \mathrm{~N}$

$35.6 \mathrm{~N}$

Breakdown data

\begin{tabular}{ccccccccc}
\multicolumn{4}{c}{ samples } & ranked in decreasing sharpness \\
A & B & G & E & I & F & H & J & K \\
A & B & E & G & F & H & I & J & K
\end{tabular}

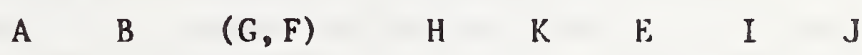

Of more significance is the comparison of characterization of edges as hazardous or safe, and here the correspondence in the two methods is considered excellent: for the $17.8 \mathrm{~N}$ force, electrical breakdown correctly classified 8 of the 9 samples; for the $35.6 \mathrm{~N}$ force, all 9 samples were correctly classified. In figure 6 a horizontal line at approximately 0.465 $\mathrm{mm}$ is used to separate the data into hazardous and safe regions. (If it is desirable to correlate breakdown data with skin cut data obtained at higher forces, another 1 ine can be arbitrarily drawn.)

Attempts 50 compare the breakdown data for the special conical points with results of other testing were inconclusive because of insufficient data.

That breakdown in the present work was sensitive to sample geometry if the polarity on the sample were made negative, but not if made positive, is explained thusly: With specimen polarity positive, for the relatively

B. J. McGuire, J. R. Sorrells, and J. D. Moore, "Resistance of Human Skin to Puncture and Laceration", NBS Report NBSIR 73-123 (Feb. 10, 1973). 
small voltage and gap lengths used, breakdown depends predominantly on the composition of the air. If the applied voltage and gap length we re made sufficiently large, the results might depend on sample geometry as well. On the other hand, when specimen polarity is negative, it acts as a cathode supplying charge carriers which facilitate the breakdown process. Electrical breakdown then occurs at smaller macroscopic electric fields (greater gap lengths) and depends on specimen geometry as well as the air composition.

\section{CONCLUSIONS}

Electrical breakdown in air can be used effectively to characterize sharp metallic edges, and it appears to have limited usefulness for characterizing sharp metallic points.

When relatively low applied voltages and small gap lengths are used, as in the present work, the polarity on the specimen must be made negative.

The results of the present work on special metallic rounded edges are in good agreement with previous human skin-cut data obtained for the same rounded edges.

\section{RECOMMENDATIONS}

1. Continuance of work on this project is considered worthwhile.

2. Although electrical breakdown has been proven effective for characterizing sharp metallic edges, the results for points, while considered fair, are not as convincing, and further work is desirable: higher applied voltages and gap lengths, and a more sensitive current indicator may improve the results. Additional tests on skin using a larger assortment of points may also be desirable for purposes of comparison with breakdown data.

3. Exposed edges and points on consumer products may not be bare metal, but lacquered or painted. These coatings are electrically nonconductive and also may alter the morphology of the edge or point. In any event, breakdown phenomena are expected to be strongly affected by the coatings and should be investigated. It may be desirable to investigate the effect on breakdown of an additional thin coating of an electrical conductor.

4. Many toys are fabricated in such a way that exposed edges are bare metal. Here, an instrument (based on breakdown) designed and developed for field use should be useful as a rapid accept/reject inspection method. 
Appendix: Calculation of electric field at the tip of a hyperboloidal point-to-plane gap.

$E_{0}$, the fleld at the tip of the hyperbololdal point is

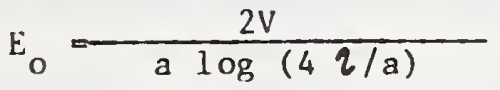

where $V$ is the applied voltage, a is the focal distance at the tip and $Z$ is the gap length. 


\section{Acknowl edgment}

The author acknowledges the contributions to this work of M. L. Greenough who suggested the problem and carried out most of the experimental work. Thanks are due Dr. 0. Petersons for useful discussion. 


\section{Bibliography}

Loeb, Leonard B., Electrical Coronas (University of California Press, Berkeley and Los Angeles, 1965). This large book is a compilation of informative but widely scattered literature on the exceedingly complex subject of electrical breakdown in gases, with emphasis on the basic physical processes. A difficult book to comprehend, descriptions are much too detalled for all but the most ardent devotees of the breakdown art. Nevertheless, the book is a useful reference source and does impart an appreciation for the many experimental parameters which govern the breakdown process.

Miyoshi, Y., ibid, pp. 383-392.

A report of an intensive study of the point (usually negative)-to - plane cornona over a very extended range of point diameters, gap lengths, point materials and pressures in clean dry air.

Tamura, T., Proc. Phys. Soc. (Japan) 16, 2503 (1961); 17, 1434 (1962); Jap. J. Appl. Phys. 2, 492 (1963).

Accounts of theoretical and experimental work in air and other gases of breakdown at positive needle points, in which photoelectric ionization of the gas is a determining factor. Ef fects of gas pressure and point radil on the absorption of photons by the gas are included.

Loeb, L. B., Parker, J. H., Dodd, E. E., and English, W. N., Rev. Sc1. Instr., 21, 42 (1950).

Contains the results of a calculation of the axial field for a point, representated by the hemispherically capped cylinder, against an infinite plane.

Loeb, Leonard B., Basic Processes of Gaseous Electronics (University of California Press, Berkeley and Los Angeles, 1955).

Gives a detalled treatment of the fundamentals of electrical carriers in gases. Field ionization, radiation, photoelectric ionization, diffusion, impact lonization, gas pressure, recombination and space charges all participate.

Hemstein, W., Ach. Elektrotech, 45 209, 279 (1960). 
Reports on studies of the discharge threshold potential of positive spherical points of various radil as a function of gap length. Both planes and concentric spheres were used as cathodes.

Bowd ler, G. W., Measurements in High-Voltage Test Circuits (Pergamon Press, New York and Oxford, 1973).

An easily readable treatise concerned mainly with experimental techniques in high-voltage measurements, it contains useful sections on application to corona and associated breakdown phenomena. 


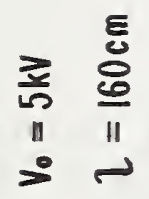
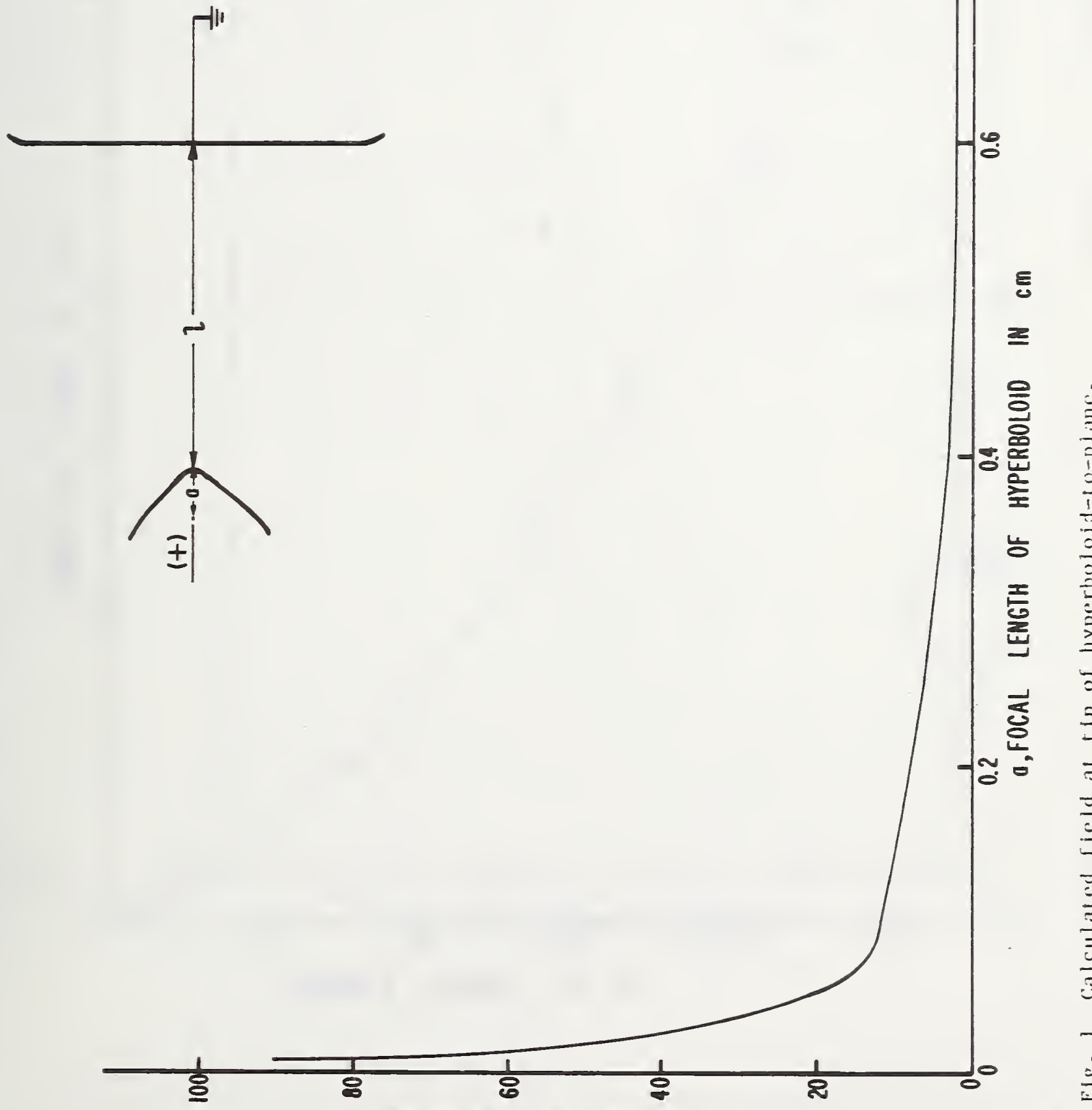


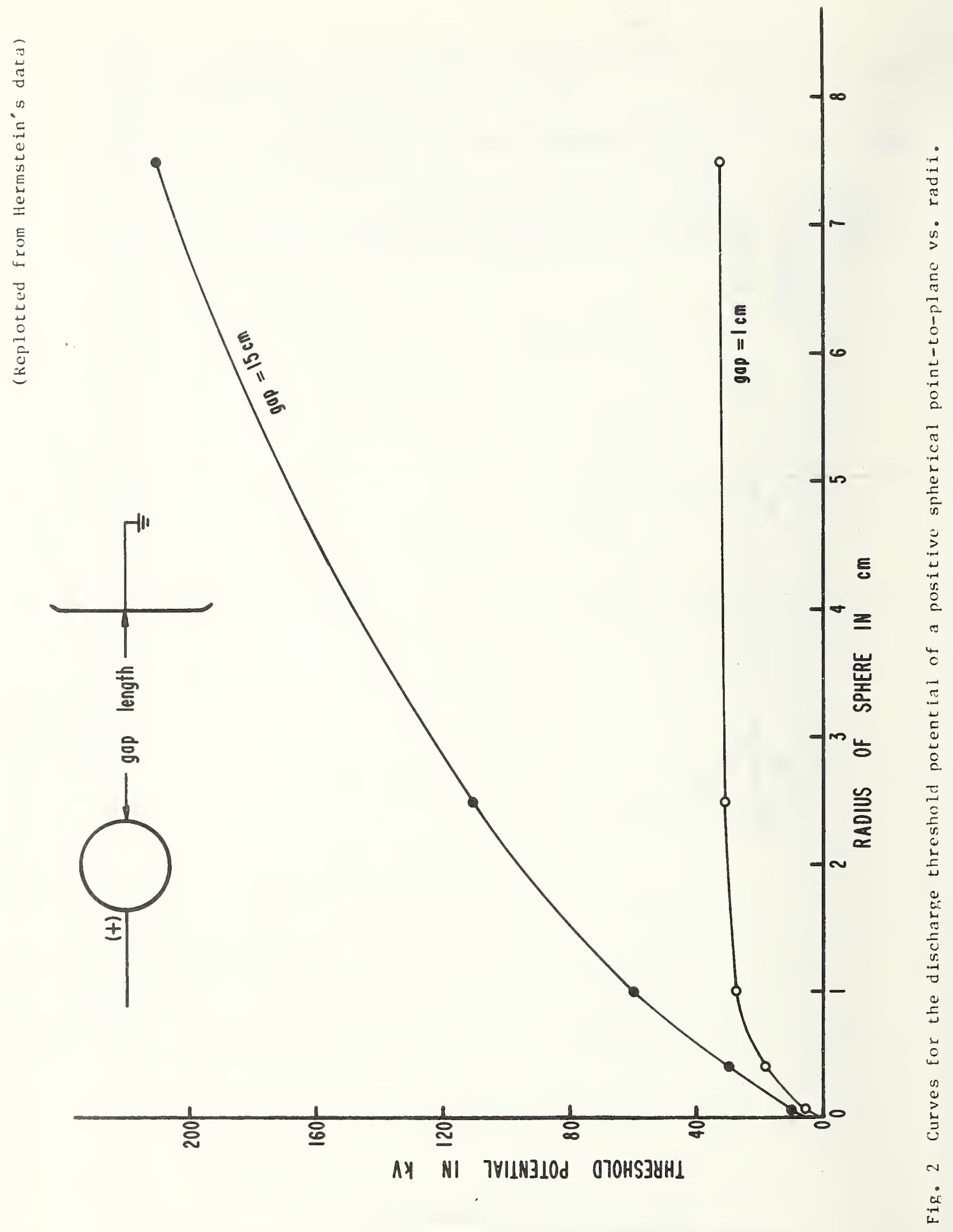




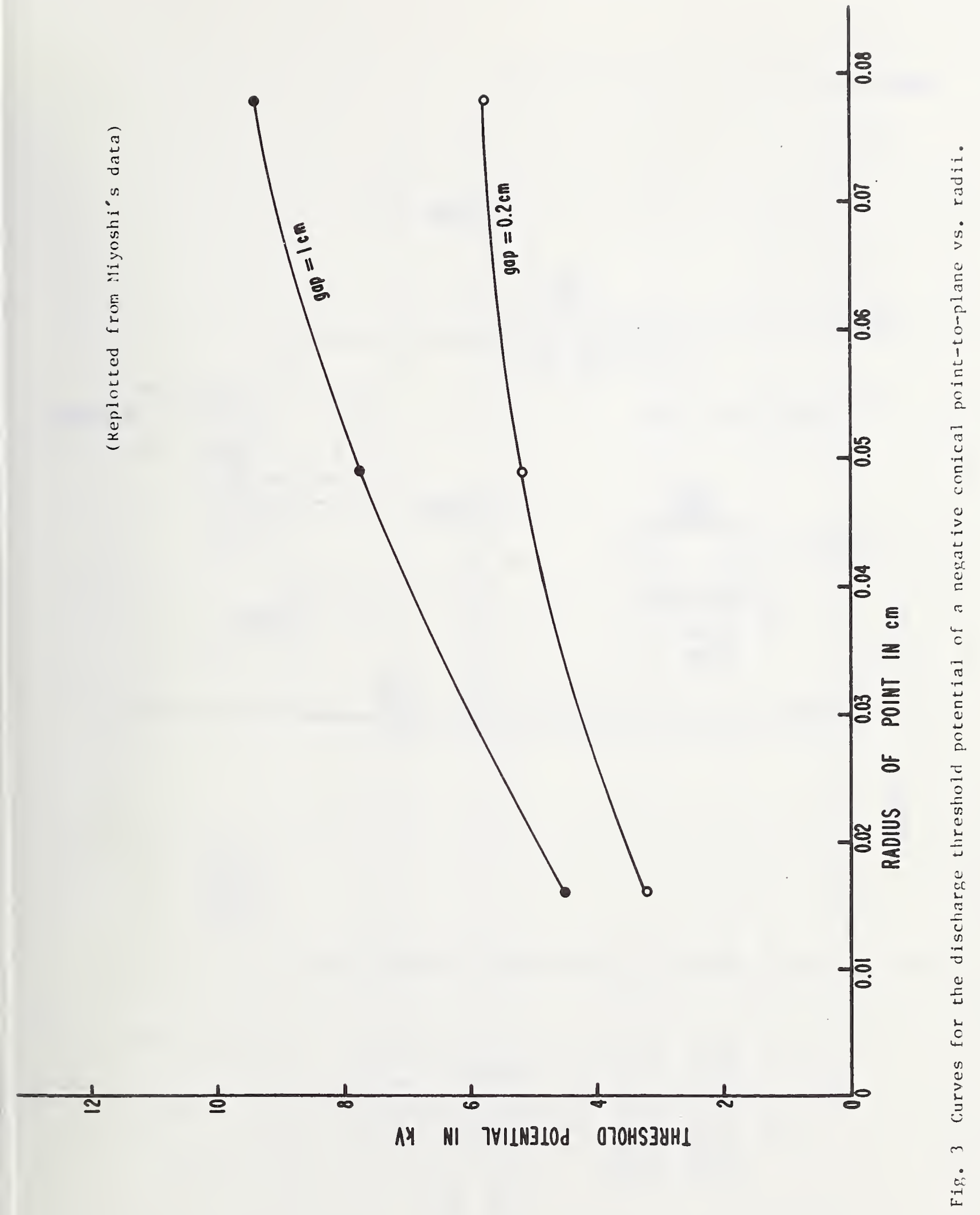




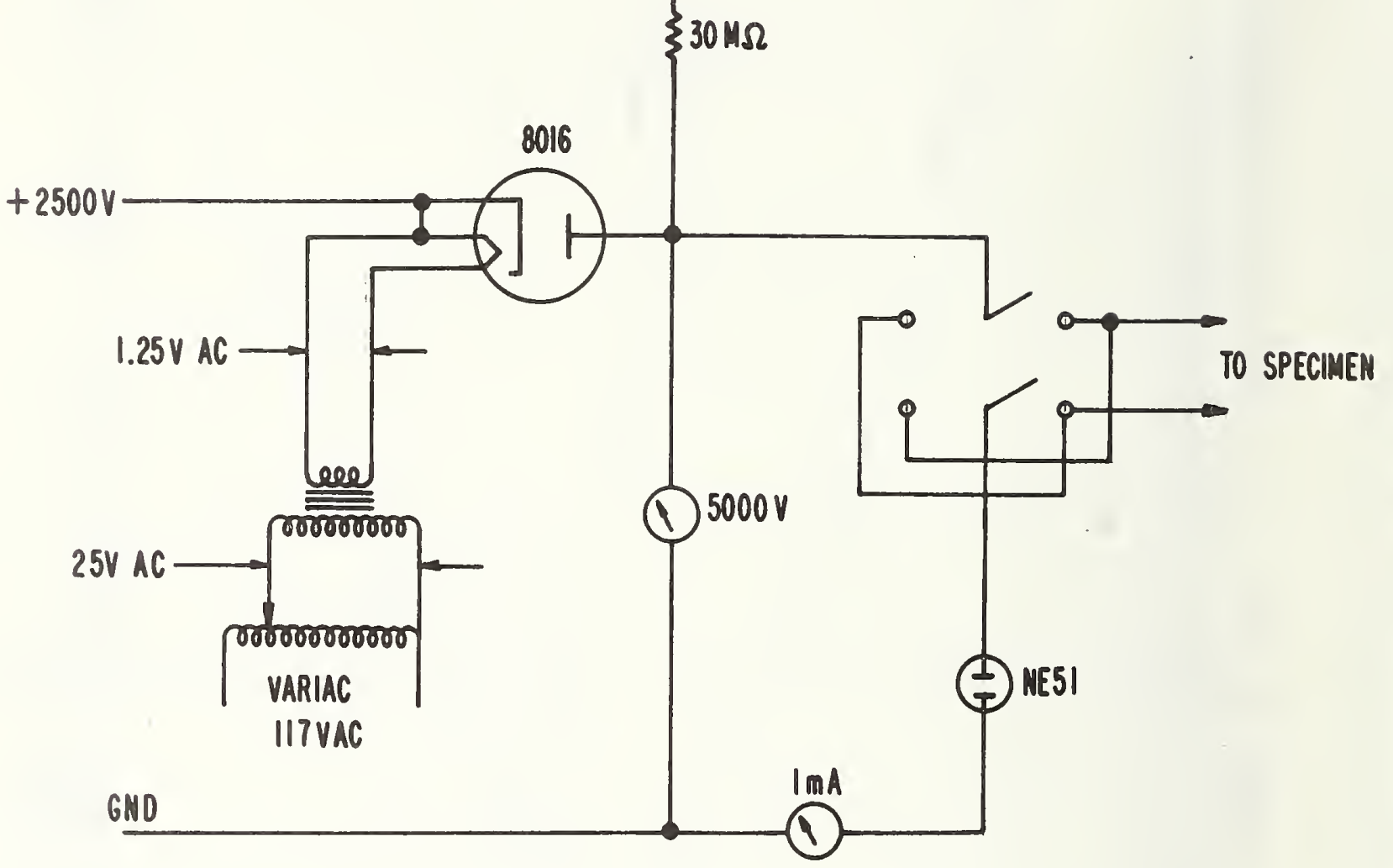

Fig. 4 Circuit diagram of high-voltage breakdown tester. 


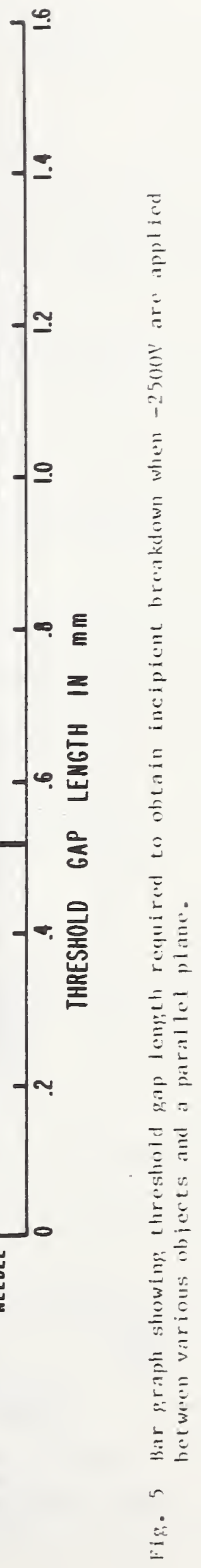




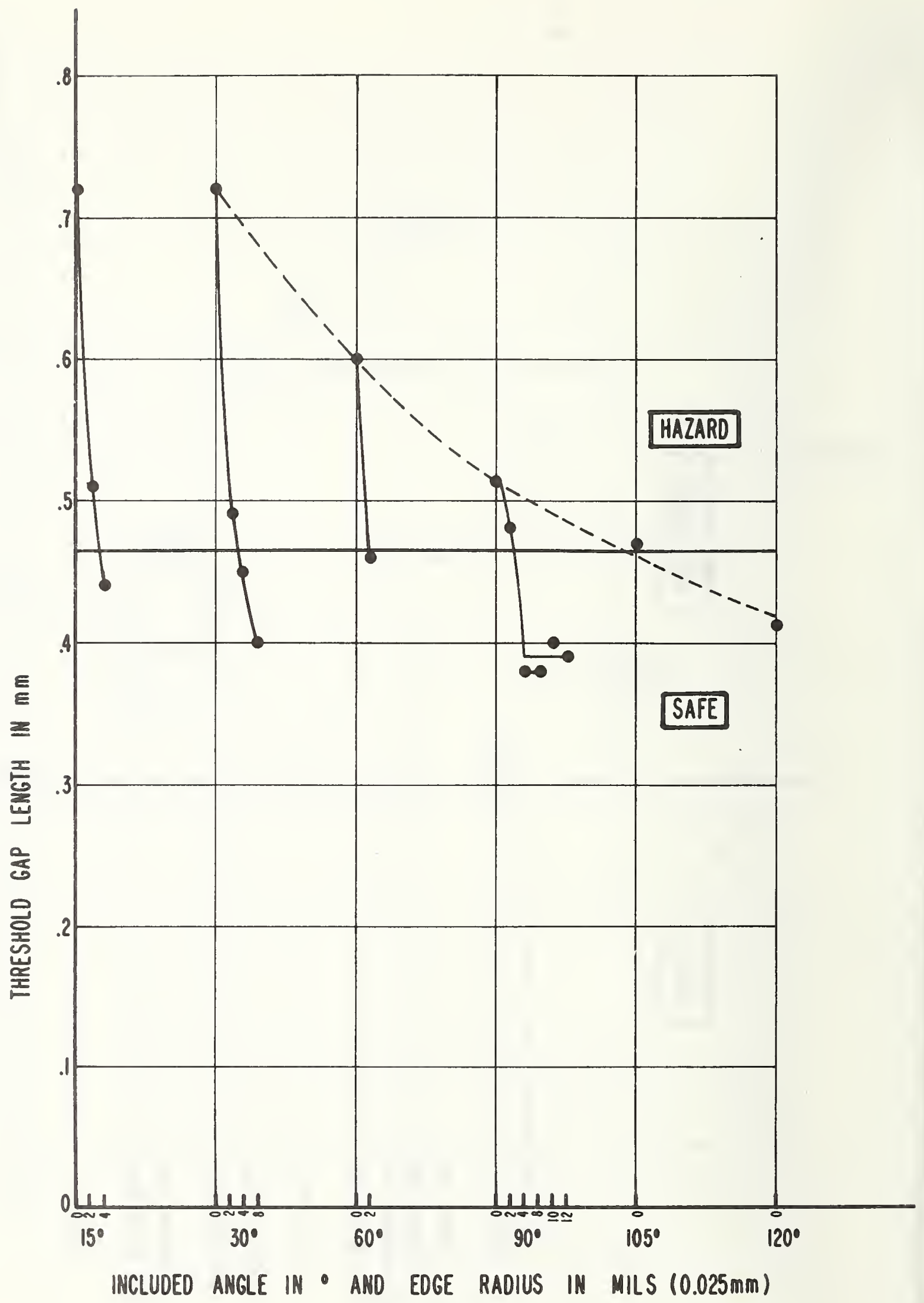

Fig. 6 Curves of threshold gap length for rounded edges of known included angles and edge radii. Each solid curve is for a set of edges having equal angles, but different radii; the dashed curve is for edges fabricated as, sharp as practicable. 


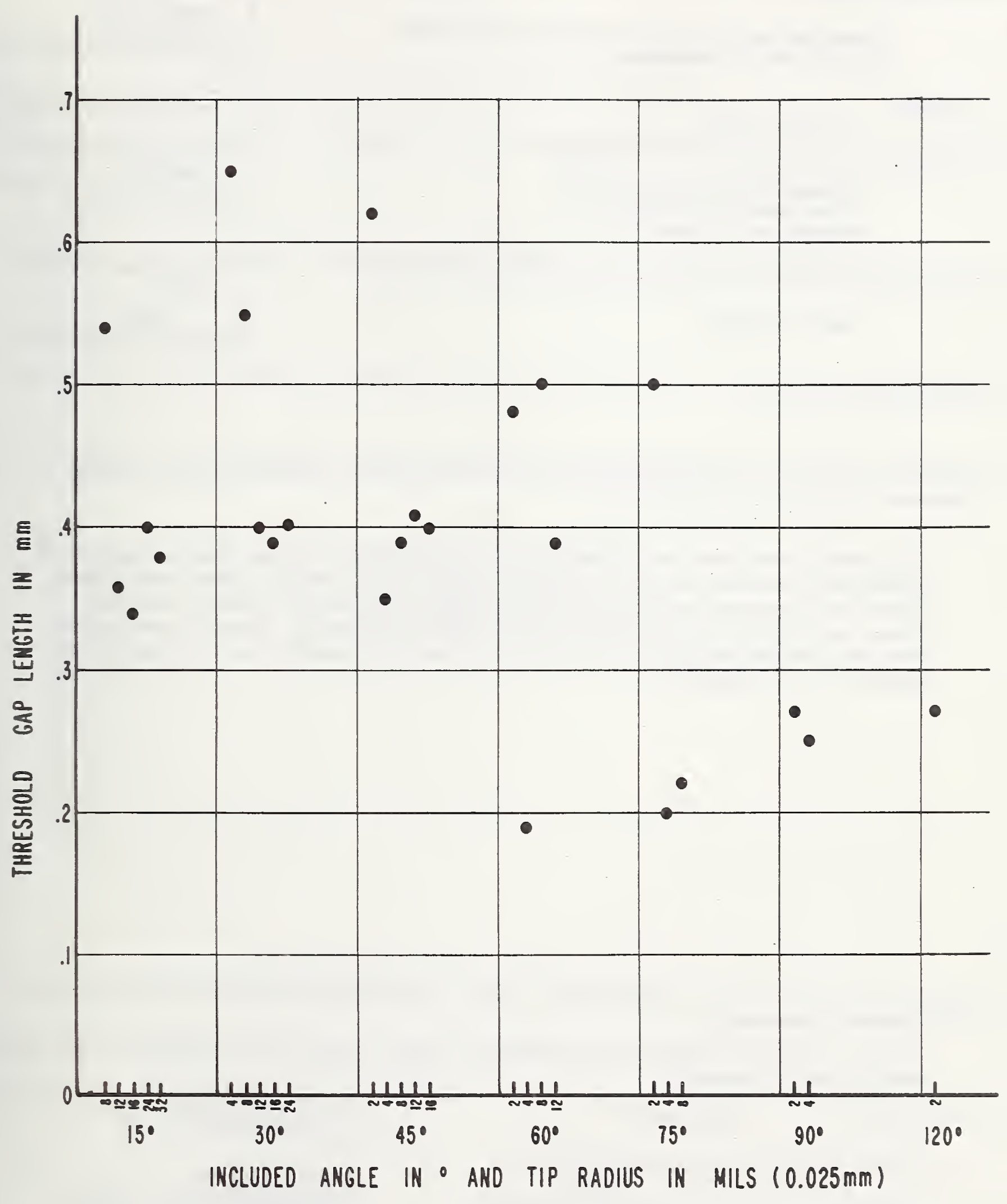

Fig. 7 Threshold gap length for conical points of known included angles and edge radii. 
NBS-114A (REV. 7-73)

\begin{tabular}{|c|c|c|c|}
\hline $\begin{array}{l}\text { U.S. DEPT. OF COMM. } \\
\text { BIBLIOGRAPHIC DATA } \\
\text { SHEET }\end{array}$ & $\begin{array}{l}\text { 1. PUBLICATION OR REPORT NO. } \\
\text { NBSIR 75-908 }\end{array}$ & $\begin{array}{l}\text { 2. Gov't Accession } \\
\text { No. }\end{array}$ & 3. Recipient's Accession No. \\
\hline \multicolumn{3}{|l|}{ 4. TITLE AND SUBTITLE } & $\begin{array}{l}\text { 5. Publication Date } \\
\text { August } 1975\end{array}$ \\
\hline \multicolumn{3}{|c|}{$\begin{array}{l}\text { Characterization of Sharp Edges and Points } \\
\text { by Electrical Breakdown }\end{array}$} & 6. Performing Organization Code \\
\hline \multicolumn{3}{|l|}{ 7. AUTHOR(S) } & 8. Performing Organ. Report No. \\
\hline \multirow{2}{*}{\multicolumn{3}{|c|}{$\begin{array}{l}\text { 9. PERFORMING ORGANIZATION NAME AND ADDRESS } \\
\text { NATIONAL BUREAU OF STANDARDS } \\
\text { DEPARTMENT OF COMMERCE } \\
\text { WASHINGTON, D.C. } 20234\end{array}$}} & $\begin{array}{l}\text { 10. Project/Task/Work Unit No. } \\
4460122\end{array}$ \\
\hline & & & 11. Contract/Grant No. \\
\hline \multirow{2}{*}{\multicolumn{3}{|c|}{ 12. Sponsoring Organization Name and Complete Address (Street, City, State, ZIP) }} & $\begin{array}{l}\text { 13. Type of Report \& Period } \\
\text { Covered } \\
\text { Final }\end{array}$ \\
\hline & & & 14. Sponsoring Agency Code \\
\hline
\end{tabular}

16. ABSTRACT (A 200-word or less factual summary of most significant information. If document includes a significant bibliography or literature survey, mention it here.)

Experiments were made to determine the feasibility of using the phenomenon of electrical breakdown in air to characterize sharp metallic edges and points. A fixed voltage was applied between a sample edge or point and a parallel plane, and threshold gap length for breakdown observed. Results were quite favorable for edges, but not for points, and the polarity on the sample was required to be negative.

17. KEY WORDS (six to twelve entries; alphabetical order; capitalize only the first letter of the first key word unless a proper name; separated by semicolons)

Consumer products; electrical breakdown; gases; hazard; high voltage; sharp edges; sharp points; threshold

\begin{tabular}{|c|c|c|}
\hline 18. AVAILABILITY & $\begin{array}{l}\text { 19. SECURITY CLASS } \\
\text { (THIS REPURT) }\end{array}$ & 21. NO. OF PAGES \\
\hline[] For Official Distribution. Do Not Release to NTIS & UNCL ASSIF IED & 20 \\
\hline $\begin{array}{l}\text { [-] Order From Sup. of Doc., U.S. Government Printing Office } \\
\text { Washington, D.C. } 20402, \mathrm{SD} \text { Cat. No. C } 13\end{array}$ & $\begin{array}{l}\text { 20. SECURITY CLASS } \\
\text { (THIS PAGE) }\end{array}$ & 22. Price \\
\hline $\begin{array}{l}\text { X) Order From National Technical Information Service (NTIS) } \\
\text { Springfield, Virginia } 22151\end{array}$ & UNCLASSIFIED & $\$ 3.25$ \\
\hline
\end{tabular}




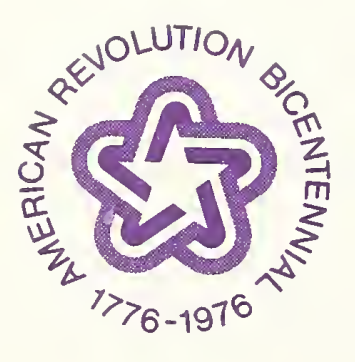

